\title{
KORELASI PROGRAM PENGELOLAAN PENYAKIT KRONIS BADAN PENYELENGGARAJAMINAN SOSIAL KESEHATAN TERHADAP KUALITAS HIDUP PASIEN di UNEJ MEDICAL CENTER
}

\section{Correlation of Chronic Disease Management Program Agency of Health Social Guarantees in The Quality of Patient's Life in Unej Medical Center}

\author{
${ }^{1}$ Ida Srisurani Wiji Astuti, ${ }^{2}$ Adhang Isdyarsa, ${ }^{3}$ Cicih Komariah \\ ${ }^{123}$ Public Health Department, Faculty of Medicine,Universitas Jember, Jember, Indonesia \\ dr.rani82@yahoo.com; 081357484568
}

\begin{abstract}
Prolanis BPJS (the program of Chronic Disease Management by Social Security Health Agency) was launched for financing efficiency for chronic disease in Indonesia. The efficiency has made a noticeable impact.This study aims to observe the correlation between the program and the increase of patients' quality of life as a result of the implementation of Prolanis BPJS. The research deployed cross sectional analytic approach in which data was collected in January 2017.During the research, 2 (two) types of questionnaire such as questionnaire of service quality based on the SERVQUAL (Service Quality) and the SF-36 questionnaire related to the quality of life were distributed. A total of 22 respondents were involved through total sampling method to identify both the value of perception and expectations of each respondent towards the quality of primary health care facilities in Unej Medical Center. Spearman method was implemented for data analysis reportingthe findings that in general the quality of service provided by PROLANIS BPJS indicated no correlation with the patients' quality of life at UMC (p) 0,072,and (r) 0,391. Eight dimensions of life quality were examined, and only two of them were showed correlation with the quality of service provided, namely: the dimensions of physical function and bodily pain.
\end{abstract}

Keywords : Prolanis, BPJS, Quality of life

Abstrak

Prolanis BPJS (Program Pengelolaan Penyakit Kronis Badan Penyelenggara Jaminan Sosial) Kesehatan dicanangkan dalam rangka efisiensi pembiayaan penyakit kronis di Indonesia. Dampak dari efisiensi tersebut tentu ada. Penelitian ini bertujuan ingin mengetahui sejauh mana korelasi program tersebut terhadap peningkatan kualitas hidup pasien sebagai dampak dilaksanakannya prolanis oleh BPJS. Penelitian ini menggunakan pendekatan analitik cross sectional. Data dikumpulkan selama bulan Januari 2017. Instrumen penelitian memakai 2 jenis kuesioner yaitu kuesioner mutu pelayanan berdasarkan SERVQUAL (ServiceQuality), dan kualitas hidup menggunakan kuesioner SF36.Sampel pada penelitian merupakan bagian dari populasi pasien DM tipe 2 dan hipertensi yang juga pengguna layanan kesehatan BPJS di UMC (Unej Medical Center), Kecamatan Sumbersari, Kabupaten Jember, Provinsi Jawa Timur. Sebanyak 22 responden ${ }^{123}$ Ida Srisurani Wiji Astuti, Adhang Isdyarsa, dan Cicih Komariah adalah Public Health Department, Faculty of Medicine,Universitas Jember, Jember, Indonesia 
melalui metode total sampling ditelusur untuk mengetahui nilai persepsi dan nilai harapan masing-masing terhadap mutu pelayanan faskes primer di Universitas Jember tersebut. Analisis data menggunakan metode Pearson dikarenakan data berdistribusi normal. Hasil uji normalitas didapatkan nilai signifikansi untuk kualitas hidup $\mathrm{p}=0,202$ dan untuk mutu pelayanan $\mathrm{p}=0,980$ sehingga nilai signifikansi keduanya bernilai $\mathrm{p}>0,05$. Ditemukan bahwa mutu pelayanan yang diberikan oleh Prolanis BPJS tidak memiliki korelasi bermakna (nilai $\mathrm{p}=0,072$ ) terhadap kualitas hidup dari pasien di UMC secara umum. Delapan dimensi kualitas hidup yang diteliti, hanya dua yang berkorelasi dengan mutu pelayanan yang diberikan. Kedua dimensi yang memiliki kekuatan korelasi sedang tersebut adalah dimensi fungsi fisik $(r=0,524)$ dan dimensi nyeri tubuh $(r=0,429)$.

Kata kunci : Prolanis, BPJS, kualitas hidup

\section{PENDAHULUAN}

Program pengelolaan penyakit
kronis adalah sistem pelayanan
kesehatan dan pendekatan proaktif yang
dilaksanakan secara terintegrasi dengan
melibatkan peserta, fasilitas kesehatan
dan BPJS kesehatan.

Penurunan kualitas hidup penderita, manajemen diabetes dan hipertensi yang sangat mahal merupakan faktor yang memaksa pemerintah Indonesia mengadopsi sistem seperti di Amerika dan Inggris. Sistem tersebut adalah DPP (Diabetic Prevention Program) dan BPLB (Blood Pressure Leadership Board) guna memberikan pelayanan khusus bagi penderita DM tipe 2 dan hipertensi pada layanan kesehatan primer. Program nasional di Indonesia itu diberi nama program pengelolaan penyakit kronis (PROLANIS) yang berada di bawah naungan BPJS Kesehatan. Setelah dilakukan kajian terhadap pembiayaan PROLANIS dan beberapa program BPJS yang lain, pemerintah berhasil menghemat biaya hingga $\mathrm{Rp}$ 1,58 trilyun per tahun. Angka tersebut merupakan jumlah yang cukup bermakna bagi efisiensi pembiayaan dibidang kesehatan (Laporan Akuntabilitas Kinerja PPJK, 2015).

Data diatas tidak sejalan dengan penelitian yang dilakukan Sari (2014) tentang efektifitas PROLANIS. Penelitian tersebut menyimpulkan bahwa PROLANIS dinilai kurang efektif dilihat dari beberapa indikator, seperti perubahan kadar gula darah puasa, kadar HbA1c, dan indeks masa tubuh. Berdasarkan penjelasan diatas, peneliti ingin meneliti tentang efektifitas PROLANIS ditinjau dari aspek mutu pelayanan oleh karena PROLANIS merupakan program yang termasuk dalam mutu pelayanan kualitas medik dari BPJS. Mengacu pada latar belakang diatas peneliti menyimpulkan untuk mengambil judul penelitian efektifitas PROLANIS terhadap kualitas hidup pasien diabetes tipe 2 di Unej Medical Center (UMC).

1. Mengetahui pengaruh mutu pelayanan PROLANIS terhadap kualitas hidup dari pasien DM tipe 2 dan hipertensi.

2. Mengetahui efektifitas PROLANIS di UMC.

\section{METODE}

Jenis penelitian ini termasuk dalam penelitian deskripsi analitik. Metode yang digunakan adalah kuesioner dengan pendekatan cross-sectional yaitu mengambil data pada satu waktu. (Budiharto, 2008). 
Alat ukur yang digunakan oleh peneliti adalah berupa kuesioner. Sedangkan tujuan dari penelitian ini untuk menganalisis korelasi mutu pelayanan PROLANIS terhadap kualitas hidup pasien DM tipe 2 dan hipertensi di UMC.

Penelitian ini dilakukan di tempat dan waktu yang berbeda sesuai dengan kesanggupan dari responden, yaitu :

a. Home visit dengan mendatangi rumah responden yang dilakukan mulai tanggal 16 Januari 2017;

b. Unej Medical Center bersamaan dengan aktifitas klub PROLANIS pada tanggal 27 Januari 2017.

\section{Sampel Penelitian}

Sampel pada penelitian ini adalah bagian dari populasi pasien DM tipe 2 dan hipertensi yang juga pengguna layanan kesehatan BPJS di UMC, Kecamatan Sumbersari, Kabupaten Jember, Provinsi Jawa Timur. Penelitian ini peneliti menggunakan metode total sampling.

Teknik pengambilan sampel yang digunakan pada penelitian ini adalah total sampling. Responden dipilih berdasarkan keikutsertaannya dalam PROLANIS. Responden akan menjawab langsung pertanyaan kuesioner dari peneliti. Jumlah total responden yang didapat adalah 22 pasien baik DM tipe 2 dan hipertensi.

a. Variabel bebas

Variabel bebas adalah variabel yang yang menyebabkan terjadinya perubahan pada variabel lain. Variabel bebas pada penelitian ini adalah mutu pelayanan yang didapatkan melalui kuesioner SERVQUAL. SERVQUAL meliputi : tangibility (bukti fisik), reability (handal), responsiveness (tanggap), assurance (jaminan), empaty (perhatian). Responden diminta untuk menjawab pertanyaan wawancara struktural. Didapatkan hasil nilai harapan dan nilai persepsi mutu pelayanan.

b. Variabel terikat

Variabel terikat adalah variabel yang dipengaruhi oleh variabel lain. Variabel terikat dalam penelitian ini adalah kualitas hidup pasien yang didapatkan melalui wawancara terstruktur dengan menggunakan Short Form 36 (SF-36). Hasil wawancara didapatkan nilai kualitas hidup dari pasien DM tipe 2 dan hipertensi peserta BPJS di UMC.

\section{Pengumpulan Data}

a. Sumber Data

Data penelitian ini merupakan data primer yang didapatkan dengan mewawancarai responden dengan bantuan kuesioner. Kuesioner yang digunakan dalam penelitian ini terdiri dari dua bagian yaitu: bagian pertama berhubungan dengan mutu pelayanan dari program PROLANIS berdasarkan SERVQUAL (Service Quality), bagian kedua yang berhubungan dengan kualitas hidup berdasarkan pada kuesioner SF-36.

b. Teknik Pengumpulan Data

Peneliti menggunakan teknik wawancara terstruktur untuk mendapatkan data primer dari responden. Wawancara dilakukan oleh orang lain yang dipercaya peneliti dan diberi pengenalan dan pelatihan dalam memahami alat yang digunakan.

c. Alat Pengumpulan Data

Peneliti menggunakan lembar kuesioner sebagai alat pengumpulan data. Lembar kuesioner dalam penelitian ini terdiri dari dua jenis yaitu lembar kuesioner untuk informasi mutu 
PROLANIS BPJS dan lembar kuesioner kualitas hidup dari pasien DM tipe 2 dan hipertensi. Kedua kuesioner saling terkait agar nantinya dapat dihubungkan hasilnya menjadi korelasi kualitas hidup pasien dengan efektivitas $\mathrm{P}$ ROLANIS dalam bidang mutu pelayanan.

\section{Analisis Data}

Data yang didapat kemudian diolah sesuai dengan standar masingmasing kuesioner. Data-data yang diolah tersebut sebelumnya dikonfersi menjadi nilai skor dengan hasil numerik. Penilaian skor kedua kuesioner adalah sebagai berikut :

a. SERVQUAL

Dalam penelitian ini SERVQUAL digunakan untuk meneliti mutu pelayanan dari PROLANIS. Mutu pelayanan didapatkan dari sebuah gap yang disebut gap 5. Gap 5 adalah selisih antara nilai persepsi responden dari pelayanan yang diterima dikurangi dengan nilai harapan responden terhadap pelayanan yang diinginkan. Nilai persepsi adalah nilai yang didapatkan dari pasien terhadap pelayanan yang mereka terima. Nilai harapan adalah nilai yang diberikan pasien untuk fasilitas kesehatan berdasarkan pada keinginan mereka. Pertanyaan yang diajukan adalah sama dengan alat yang sama. Langkah pertama adalah memberikan pertanyaan guna mendapatkan persepsi pasien, yang kedua untuk mendapatkan harapan pasien (Roohi, et al., 2011).

Nilai gap didapatkan dari masing lima dimensi disetiap aspek persepsi dan harapan kemudian dijumlahkan lalu diambil rata-rata nilai total gap. Skor dalam kuesioner ini berdasarkan dengan skala Likert, seperti berikut:

$$
\begin{array}{ll}
\text { sangatburuk } & =0 ; \\
\text { buruk } & =25 ; \\
\text { cukupbaik } & =50 ; \\
\text { baik } & =75 ; \\
\text { sangatbaik } & =100 .
\end{array}
$$

Nilai gap yang didapatkan memiliki arti jika bernilai positif atau mendekati nol, maka tingkat kepuasan atau mutu pelayanan berdasarkan persepsi pelanggan semakin baik. Nilai negatif memiliki arti bahwa mutu pelayanan masih belum memenuhi harapan atau kepuasan dari pasien (Pena, et al., 2013).

\section{b. SF-36}

Short Form-36 digunakan untuk mengetahui tingkat kualitas hidup pasien DM tipe 2 dan hipertensi. Berdasarkan pedoman yang digunakan, pembagian skor SF-36 adalah sebagai berikut:

Tabel 3.2 Skor pertanyaan SF-36

\begin{tabular}{lcc}
\hline \multicolumn{1}{c}{ Nomor pertanyaan } & Jumlah pilihan jawaban & Interval \\
\hline $1,2,20,22,32,33,34,35,36$ & 5 & 25 \\
$3,4,5,6,7,8,9,10,11,12$ & 3 & 50 \\
$13,14,15,16,17,18,19$ & 2 & 100 \\
$21,23,24,25,26,27,28,29,30,31$ & 6 & 20 \\
\hline
\end{tabular}

Sumber: Quality of Life Research, Hawthrone, G. et. al, 2007

Setelah nilai dari masing-masing pertanyaan telah ditentukan maka dikelompokkan berdasarkan dengan dimensi masing-masing. Pada tabel 3.3 menunjukkan nomor pertanyaan di setiap dimensinya, seperti berikut : 
Tabel 3.3 Skor dimensi SF-36

\begin{tabular}{lccc}
\hline \multicolumn{1}{c}{ Sub variabel } & $\begin{array}{c}\text { Jumlah } \\
\text { pertanyaan }\end{array}$ & \multicolumn{2}{c}{ Nomor pertanyaan dari tabel 3.2} \\
\hline Fungsifisik & 10 & $3,4,5,6,7,8,9,10,11,1213,14,15,16$ \\
\hline Nyeritubuh & \multicolumn{3}{l}{21,22} \\
Kesehatan secara umum & & 6 & $1,2,33,34,35,36$ \\
Vitalitas & 4 & $23,27,29,31$ \\
Fungsisosial & 2 & 20,32 \\
Kesehatanemosional & & 3 & $17,18,19$ \\
Kesehatan mental & 5 & $24,25,26,28,30$ \\
\hline \multicolumn{1}{l}{ Keterbatasan fisik } & 5 & \\
\hline
\end{tabular}

Nilai skor akhir ditentukan dengan jumlah total konversi dari tabel 3.2 kemudian dikelompokkan berdasarkan tabel 3.3 dan dibagi dengan jumlah pertanyaan tiap dimensi.

\section{Uji Statistik}

Data dianalisis menggunakan program SPSS. Uji yang digunakan untuk menguji korelasi dua sampel dependen dan independen dengan bentuk data numerik adalah uji korelasi Pearson dikarenakan data terdistribusi secara normal. Uji korelasi juga dilakukan pada delapan dimensi kualitas hidup untuk mengetahui dimensi yang memiliki korelasi dengan mutu pelayanan.

\section{HASIL PENELITIAN}

Penelitian tentang efektifitas PROLANIS terhadap kualitas hidup pasien ini menggunakan dua buah kuesioner yang berbeda. Kuesioner terdiri dari SERVQUAL sebagai pengukur mutu pelayanan dan SF-36 sebagai pengukur kualitas hidup responden. Kuesioner tersebut diajukan kepada 22 peserta PROLANIS BPJS. Responden tersebut terdiri dari 11 orang laki-laki dan 11 perempuan. Jumlah skor total dari masing-masing kuesioner SERVQUAL dan SF-36 adalah hasil skoring yang digunakan peneliti untuk diolah. Pengumpulan data selanjutnya memakai uji normalitas menggunakan uji Saphiro-Wilk karena jumlah sampel yang didapat berjumlah kurang dari 50. Data selanjutnya diolah menggunakan uji korelasi dari Pearson dikarenakan distribusi data yang normal.

\section{Pengukuran Mutu Pelayanan}

Data hasil penelitian mengenai mutu pelayanan dengan menggunakan lima dimensi kualitas pelayanan Prolanis di UMC dari persepsi pengguna layanan terdapat pada tabel 4.1 dibawah ini :

Tabel 4.1 Persepsi Responden terhadap Mutu Pelayanan PROLANIS

\begin{tabular}{llll}
\hline Dimensi kualias pelayanan & Skor persepsi & Skor harapan & Gap 5 \\
\hline Fisik & 65,91 & 85,04 & $-19,13$ \\
Kehandalan & 61,08 & 73,44 & $-12,36$ \\
Daya tanggap & 63,26 & 76,70 & $-13,45$ \\
Jaminan kepastian & 57,27 & 71,59 & $-14,32$
\end{tabular}




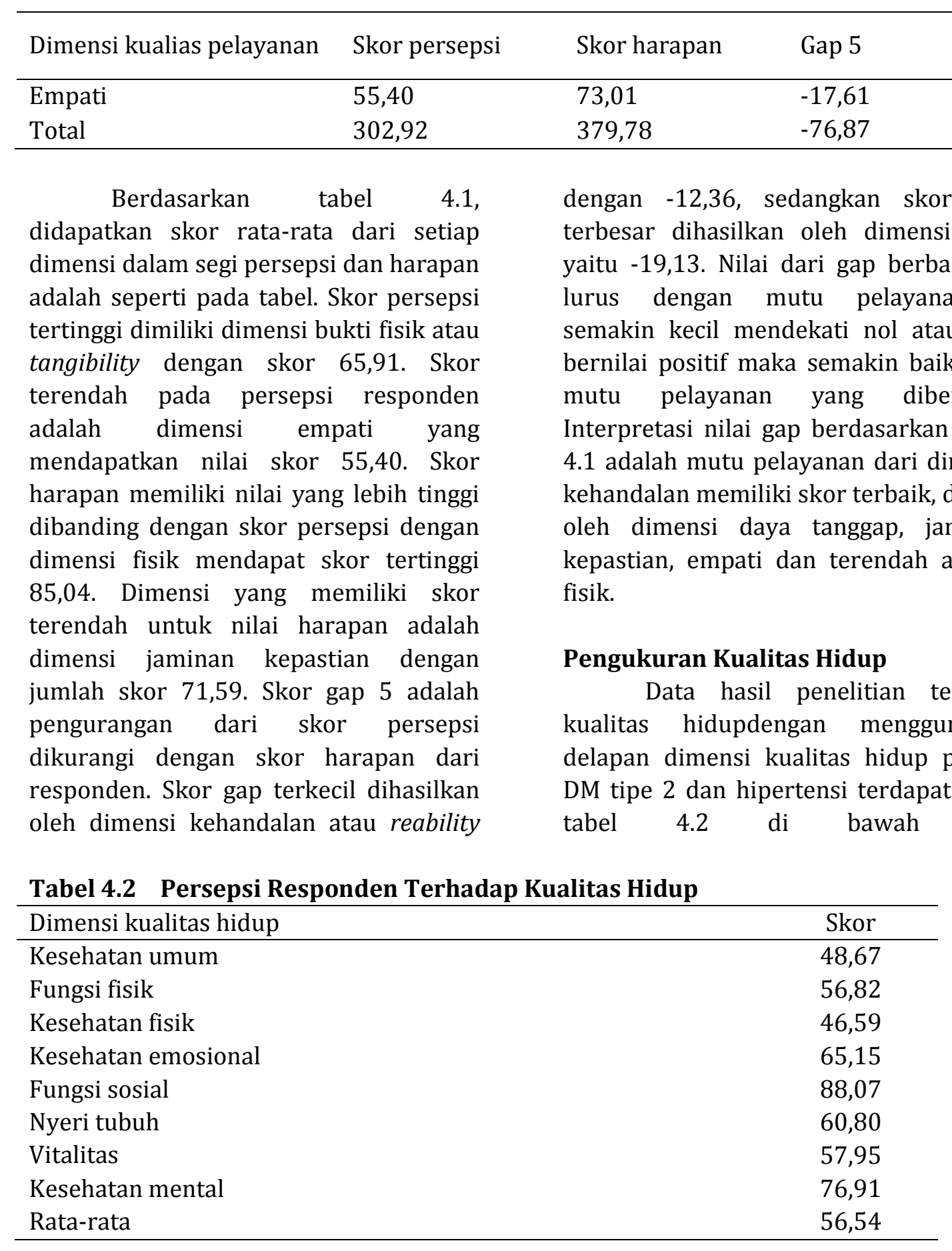

Berdasarkan tabel 4.2 diatas, setiap dimensi memiliki nilai yang setara dengan maksimal skor adalah 100 . Dimensi fungsi sosial memiliki skor tertinggi yaitu 88,07 dimana skor itu berarti hanya ada sedikit gannguan fungsi sosial dikarenakan DM tipe 2 ataupun hipertensi. Nilai tertinggi selanjutnya adalah dimensi kesehatan mental dengan 76,91, diikuti dimensi kesehatan emosional dengan 65,15 serta nyeri tubuh dengan skor 60,80. Dimensi kesehatan fisik mendapatkan nilai skor terendah yaitu 46,59, diatasnya adalah dimensi kesehatan umum atau persepsi kondisi umum yang sedang dirasakan oleh responden dengan nilai 48,67. Dimensi vitalitas dan dimensi fungsi fisik 
memiliki nilai skor 57,95 dan 56,82. Skor rata-rata dari kedelapan dimensi yang diukur mencapai nilai 56,54.

Data hasil penelitian ini merupakan data dengan skala numerik berupa skor mutu pelayanan dan skor kualitas hidup. Data yang telah terkumpul dan sudah diolah peneliti kemudian dilanjutkan dengan melakukan uji normalitas. Uji normalitas yang digunakan pada penelitian ini adalah uji Saphiro-Wilk karena jumlah sampel yang didapat kurang dari $50(\mathrm{n}<50)$. Hasil dari uji normalitas didapatkan nilai signifikansi untuk kualitas hidup $\mathrm{p}=$ 0,202 dan untuk mutu pelayanan $\mathrm{p}=$ 0,980 sehingga nilai signifikansi keduanya bernilai $p>0,05$. Hasil signifikansi tersebut menunjukkan bahwa distribusi data normal berdasarkan uji Saphiro-Wilk dan dapat dilanjutkan untuk uji korelasi Pearson (Dahlan, 2013).

Hasil pengolahan pada uji korelasi pearson didapatkan nilai korelasi (p) 0,072, nilai kekuatan korelasi (r) 0,391. Nilai korelasi $\mathrm{p}=$ 0,072 memiliki arti korelasi positif namun tidak terdapat korelasi yang bermakna antara dua variabel mutu pelayanan dan kualitas hidup. Nilai kekuatan korelasi $r=0,391$ dimana nilai tersebut memiliki arti kekuatan korelasi lemah antara dua variabel. Selanjutnya peneliti menganalisis korelasi mutu pelayanan terhadap setiap dimensi pada kualitas hidup pasien. Nilai korelasi yang didapatkan tertera pada tabel 4.3 di bawah

Tabel 4.3 Nilai Korelasi 8 Dimensi Kualitas Hidup

\begin{tabular}{lcc}
\hline \multicolumn{1}{c}{ Dimensi } & Kekuatan korelasi & Signifikansi \\
\hline Kesehatan umum & 0,171 & 0,446 \\
Fungsi fisik & 0,524 & 0,012 \\
Kesehatan fisik & 0,101 & 0,654 \\
Kesehatan emosional & $-0,196$ & 0,381 \\
Fungsi sosial & 0,051 & 0,820 \\
Nyeri tubuh & 0,429 & 0,046 \\
Vitalitas & 0,300 & 0,176 \\
Kesehatan mental & 0,402 & 0,064 \\
\hline
\end{tabular}

Berdasarkan data dari tabel 4.3 tersebut, didapatkan hasil bahwa hanya ada dua dimensi yang memiliki korelasi dengan mutu pelayananya itu dimensi fungsi fisik dan nyeri tubuh. Dimensi fungsi fisik dan dimensi nyeri tubuh berada pada rentang kekuatan korelasi sedang dengan nilai $r=0,524$ untuk fungsi fisik dan $r=0,429$ untuk nyeri tubuh.

\section{PEMBAHASAN}

Berdasarkan hasil penelitian, dari 22 responden pasien DM tipe 2 dan hipertensi didapatkan bahwa skor gap antara persepsi dan harapan responden terhadap pelayanan yang diberikan sebesar -76,87. Skor dimensi fisik memiliki nilai tertinggi diikuti oleh daya tanggap, kehandalan, jaminan kepastian dan yang terendah empati. Berdasarkan acuan yang dibuat oleh Zeithtmal dan Berry, bila nilai gap semakin besar dan positif maka semakin baik pula pelayanan yang diberikan (Pena, 2013). 
Terdapat beberapa penelitian yang sejalan dengan hasil yang diperoleh diatas. Penelitian yang pertama dilakukan pada 222 jasa pelayanan kesehatan di Iran pada tahun 2014. Penelitian ini mengatakan bahwa menciptakan suasana fisik yang bagus akan sangat mempengaruhi nilai kuantitatif atau nilai skor akhir dari sebuah pelayanan. Hal tersebut menunjukkan bahwa dimensi fisik mempengaruhi nilai persepsi paling tinggi terhadap mutu pelayanan, meski untuk pelayanan kesehatan seharusnya lebih bergantung pada proses dan interaksi ke pasiennya (Mosadeghrad, 2014).

Penelitian lain menyebutkan terdapat faktor lain yang sangat memperngaruhi hasil dari penilaian SERVQUAL. Faktor kelamin, dimana perempuan lebih memberikan hasil gap yang lebih besar dan tidak bernilai baik. Perempuan cenderung memberikan nilai persepsi yang lebih buruk daripada lakilaki. Faktor tangibility atau dimensi fisik. Faktor ini menjadi perhatian khusus bagi para pengguna jasa layanan kesehatan, karena bersifat. Hal ini diperkuat dengan tanggapan dari para responden dalam penelitian ini yang menyebutkan bahwa efisiensi dan penampilan dari tenaga keseahatan mempengaruhi rasa segan mereka (Roohi, et al., 2011).

Interpretasi dari hasil
pengolahan korelasi antara mutu pelayanan dan kualitas hidup pasien di UMC adalah tidakadanya korelasi namun memiliki arah positif dengan hubungan yang lemah. Hal ini menunjukkan bahwa tidak ada hubungan dari mutu pelayanan yang diberikan terhadap kualitas hidup dari pasien DM tipe 2 dan hipertensi. Pernyataan ini didukung oleh penelitian sebelumnya yang berjudul efektifitas pelaksanaan prolanis dalam penanganan pasien DM tipe 2 di tingkat dokter keluarga. Penelitian tersebut menyimpulkan bahwa salah satu penyebab ketidak efektifan prolanis adalah dalam segi edukasi. Edukasi yang diberikan oleh dokter belum semua pasien mengikuti nasihat yang diberikan dan belum berpengaruh banyak dalam penurunan kadar gula dan HbA1c pasien (Sari, 2014).

Berikutnya peneliti menganalisa korelasi mutu pelayanan dengan delapan dimensi kualitas hidup yang telah di dapat. Hasil yang didapatkan pun hamper sama dimana hanya ada dua dimensi yang memiliki korelasi dengan mutu pelayanan. Kedua dimensi yang memiliki korelasi adalah dimensi fungsi fisik dan nyeri tubuh dimana memilikii nterpretasi bahwa program rujuk balik dan pemantauan kesehatan memberikan dampak pada pasien.

\section{SIMPULAN}

Mutu pelayanan yang diberikan oleh PROLANIS BPJS tidak memiliki korelasi terhadap kualitas hidup dari pasien di UMC secara umum, namun terdapat korelasi pada beberapa dimensi kualitas hidup. Dimensi yang berkorelasi dengan mutu pelayanan adalah dimensi fungsi fisik dan nyeri tubuh.

\section{DAFTAR RUJUKAN}

1] American Diabetes Association. 2010. Diagnosis and Classification of Diabetes Melitus. Diabetes Care: 33(1): 562-9.

2] Astuti, I. S. W. 2016. Karakteristik Faktor-Faktor Yang Berhubungan Dengan Insidensi Diabetes Mellitus Diwilayah Kerja Puskesmas Mayang Dan Ledokombo. Makalah Orasi Ilmiah. Jember: Pertemuan 
Ilmiah Dosen Fakultas Kedokteran Universitas Jember. 15 Maret.

3] BPJS Kesehatan. 2014. Panduan Praktis Prolanis (Program Pengelolaan Penyakit Kronis). Jakarta.

4] Budiharto. 2008. Metodologi Penelitian Kesehatan dengan Contoh Bidang Ilmu Kesehatan Gigi. Jakarta: EGC.

5] Gautam, Y., A. Sharma, A. Agarwal, M. Bhatnagar, R. Trehan. 2009. A Cross-sectional Study of QOL of Diabetic Patients at Tertiary Care Hospitals in Delhi. Vol. 34 (4): 346- 350. Indian Journal of Community Medicine.

6] International Diabetic Federation. 2015. Urban Rural Prevalence Estimates. Western Pasific.

7] Kementerian Kesehatan Republik Indonesia. 2015. Laporan Akuntabilitas Kinerja. Jakarta.

8] Mosadeghrad, A.M. 2014. Factors Influencing Healthcare Service Quality. DOI: 10.15171/ijhpm.2014.65. PubMed.

9] NHS England \& Public Health England. 2015. National NHS Diabetes Prevention Programme. https://www.gov.uk/government/ news/national-nhs-diabetesinitiative-launched-in-major-bidto-prevent-illness. [Diakses pada 11 Oktober 2016].

10] NIH American Diabetes Association. 2012 Financial Help for Diabetes Care. https://www.niddk.nih.gov/health -information/diabetes/financialhelp-diabetes-care [Diakses pada 11 Oktober 2016].

11] Ningtyas, D., P. Wahyudi, dan I. Prasetyowati. 2013. Analisis Kualitas Hidup Pasien Diabetes Melitus Tipe II di RSUD Bangil
Kabupaten Pasuruan. Artikel Ilmiah Hasil Penelitian Mahasiswa.

12] Notoatmodjo, S. 2010. Metodologi Penelitian Kesehatan. Jakarta: Rineka Cipta.

13] Perkumpulan Endokrinologi Indonesia. 2015. Konsensus Pengelolaan dan Pencegahan Diabetes Melitus Tipe 2 di Indonesia. Jakarta: Pengurus Besar Perkeni.

14] Roohi, G., Hamid, A., Ali, A. A., \& Ali, A. 2011. Evaluation of Client's Expectation and Perception Gap Regarding the Quality of Primary Healthcare Service in Healthcare Centers of Gorgan. Journal of Jahrom University of Medical Sciences. Vol. 09 (03).

15] Sari, A. N. 2014. Efektivitas Pelaksanaan Program Penyakit Kronis (Prolanis) Dalam Penanganan Diabetes Melitus Tipe 2 Oleh Dokter Keluarga di Kecamatan Turi, Sleman. Skripsi. Yogyakarta: Fakultas Kedokteran Universitas Gajah Mada.

16] Smeltzer, S. C., B. G. Bare. 2008. Brunner And Sudarth's textbook of medical-surgical nursing. Agung. Jakarta: EGC.

17] Undang-Undang Republik Indonesia Nomor 40 Tahun 2004. Sistem Janiman Sosial Nasional. Jakarta.

18] Wang, J., R. Luben, K. T. Khaw, S. Bingham, N. J. Wareham, N. G. Forouhi. 2008. Dietary Energy Density Predicts the Risk of Incident Type 2 Diabetes: the European Prospective Investigation of Cancer (EPIC).

19] Yang, Dall, Halder, Gallo, Kowal, Hogan. 2012. Economic Cost of Diabetes in the U.S. Diabetes Care. DOI: $10.2337 /$ dc12-2625. Vol. 36 (4): 1033-1046. 
10 Jurnal IKESMA Volume 14 Nomor 1 Maret 2018

20] Yusra, A. 2011. Hubungan Antara Dukungan Keluarga dengan Kualitas Hidup Pasien Diabetes Melitus Tipe 2 di Poliklinik Penyakit Dalam Rumah Sakit Umum Pusat Fatmawati Jakarta. Tesis. Depok: Magister Ilmu Keperawatan Universitas Indonesia. 
